\title{
REFRACTIVE ERROR BLINDNESS IN YENAGOA, BAYELSA STATE, NIGERIA: A HOSPITAL BASED STUDY
}

\section{*I.R Azonobi}

*Department of Ophthalmology, Niger Delta University, Okolobiri Yenagoa, Bayelsa State, Nigeria

\section{Correspondence:}

Dr Azonobi I.R

Dept of Ophthalmology

Niger Delta University

Okolobiri, Yenagoa

Bayelsa State

Nigeria

E-mail: doctorazonobi2002@yahoo.com

Address: PO Box 1051, Yenagoa, Bayelsa State.

\section{ABSTRACT}

Background: Despite the priority attention giving to refractive error in vision 2020 programme, blindness due to uncorrected refractive error is relatively unexplored. The aim of this study is to determine the prevalence and causes of refractive error blindness in Yenagoa.

Method: All consecutive patients presenting to our eye clinic that were diagnosed to have refractive error over a one year period was studied. They underwent a full ocular examination including anterior and posterior segment examination, objective and subjective refraction. Objective refraction was done using a Carl Zeiss $599^{\mathrm{R}}$ autorefractometer. Information obtained included their age, sex, occupation, presenting visual acuity, history of couching and that of cataract surgery without an implant.

Statistical analysis was done manually using a scientific calculator.

Results: 1168 patients was seen during the study period and 135 persons had refractive error. Of the number with refractive error, 63 were males while 72 were females
$(M: F=1: 1.4)$. Their age ranged from 6 to 83 years with a mean of 35.7 years (SD \pm 4.102$)$. The prevalence of refractive error blindness was $0.68 \%$. High myopia accounted for $75 \%$ of the blindness while high hyperopia and aphakia accounted for $12.5 \%$ each respectively. The prevalence of low vision due to refractive error was $2.5 \%$. Myopia was responsible for half of the cases of low vision while hyperopia and astigmatism accounted for $30 \%$ and $16 \%$ respectively. Aphakia was responsible for $3.3 \%$ of low vision seen.

Conclusion: Uncorrected refractive error is potentially blinding with a prevalence of $0.68 \%$ in this population, myopia being responsible for majority of cases. Health education is needed to create awareness on the availability of refractive error services in this population in order to stem the tide of needless blindness.

Keywords: Blindness, refractive error, Yenagoa, myopia, aphakia, hyperopia. 


\section{BACKGROUND}

Refractive error (uncorrected) is one of the most common causes of blindness and low vision worldwide ${ }^{1,2}$. As a cause of blindness and low vision, it has not received much attention because most definition of blindness has been based on best corrected visual acuity. However, with the increasing use of presenting visual acuity in the definition of blindness, refractive error is becoming the second largest cause of treatable blindness after cataract ${ }^{3,4,5}$.

The magnitude of refractive error blindness and its causes varies worldwide. In Pakistan ${ }^{3}$, the prevalence of refractive error blindness was $0.2 \%$ and is due to aphakia while in China $^{6}$, the prevalence was $0.4 \%$ with blindness mainly due to myopia and hyperopia. In Ethiopia $^{2}$ with a refractive error blindness prevalence of $0.04 \%$, aphakia was the main cause of blindness, while in India ${ }^{7}$ with a prevalence of $0.21 \%$, myopia was the commonest cause of blindness.

Refractive error blindness has a profound effect on the quality of life of its sufferers leading to poor performance in schools and other career opportunities. It also reduces productivity in the workforce, creating enormous economic burden in the society $^{8}$. This burden and loss of opportunity depend on the age of the patient and the type of refractive error. The burden of refractive error defined as person years affected by blindness or visual impairment can be greater than that due to cataract because of its earlier onset ${ }^{9}$.In India, this burden has been estimated to be twice that due to cataract ${ }^{7}$.

Although a large amount of data is available on the prevalence of blindness in different parts of the world, data on the prevalence of blindness due to refractive error are not readily available because the presenting distance acuity definition of blindness is not always used ${ }^{10}$. For adequate and effective planning of refractive error services, an important component of vision 2020 it is important to know the prevalence and distribution of refractive error blindness in the affected population.

No such data is available in Yenagoa, a Niger Delta community in Nigeria. Niger Delta university teaching hospital eye clinic is the only functional ophthalmic centre in the state. As a result, most ocular problems including refractive error present here. Cases seen in this clinic may to an extent be representative of the situation in the general population. In the absence of a state wide survey on the prevalence of refractive error blindness, a hospital based study of this nature can provide useful information needed for planning eye care services. This study was thus conducted to provide this information.

\section{MATERIALS AND METHODS}

\section{Location and duration of Study}

Patients presenting to the Eye Clinic of the Niger Delta University Teaching Hospital, Okolobiri, Yenagoa, Bayelsa State over a one year period (March 2008 ï February 2009) were studied.

\section{Methods}

All consecutive patients presenting to the Eye Clinic with complaints of blurred vision for distance or asthenopic symptoms associated with improvement in their visual acuity with pin hole were refracted objectively using a Carl Zeiss 599® autorefractometer followed by a subjective refraction. Old patients with refractive error reporting back to the clinic for one complain or the other were also studied. Their presenting visual acuity 
(PVA) was measured using a snellen visual acuity chart and a full ocular examination was carried out including anterior segment examination using a Haag-Streit slit lamp biomicroscope and a posterior segment examination using a Keeler $^{\mathrm{R}}$ direct ophthalmoscope. Other information obtained from the patients included their age, sex and occupation and history of cataract surgery without intra ocular lens implantation or couching of one of both eyes. Refractive error was defined in this study as errors Ó \pm $0.50 \mathrm{DS} / \mathrm{cyl}$ in any meridian. Blindness was defined as presenting visual acuity of $<3 / 60$ in the better eye and low vision as presenting visual acuity of less than $6 / 18$ in the better eye.

\section{Statistical Analysis}

The data obtained in this study were manually analyzed using a scientific calculator. Data were presented as frequencies, percentages, means and standard deviation.

\section{RESULTS}

Over the one year period of this study, 1168 patients were seen out of which 135 were confirmed to have refractive error. Out of the 135 with refractive error, 63 were males and 72 females giving a male : female ratio of $1: 1.4$ (Table 1).

Table 1: $\quad$ Age and sex distribution of study population

\begin{tabular}{|c|c|c|c|}
\hline \multirow{2}{*}{ Age } & \multicolumn{2}{|c|}{$\operatorname{Sex}(n)$} & \multirow{2}{*}{ Total } \\
\hline & Male & Female & \\
\hline 0 ï 10 & 1 & 4 & 5 \\
\hline 11 ï 20 & 6 & 14 & 20 \\
\hline 21 ï 30 & 7 & 6 & 13 \\
\hline 31 ï 40 & 11 & 13 & 24 \\
\hline 41 ï 50 & 20 & 26 & 46 \\
\hline 51 i 60 & 6 & 8 & 14 \\
\hline 61 i 70 & 8 & - & 8 \\
\hline$>70$ & 4 & 1 & 5 \\
\hline Total & 63 & 72 & 135 \\
\hline
\end{tabular}

Their age ranged from 6 to 83 years, with a mean of 35.7 years (SD \pm 4.102).

Hypermetropia was the commonest refractive error found in the study population (36.3\%), followed by astigmatism (32.6\%) and myopia $(28.9 \%)$ respectively. Aphakia was the least form of refractive error seen (3.2\%), Table 2. 
Table 2: Distribution of refractive error in the study population

\begin{tabular}{|c|c|c|}
\hline Type of Error & Number & $\%$ \\
\hline Myopia & 39 & 28.9 \\
\hline Hyperopia & 49 & 36.3 \\
\hline Astigmatism & 44 & 32.6 \\
\hline Aphakia & 3 & 3.2 \\
\hline Total & $\mathbf{1 3 5}$ & $\mathbf{1 0 0 . 0}$ \\
\hline
\end{tabular}

There were 8 cases of refractive error blindness in the population giving a prevalence of $0.68 \%$. High myopia accounted for $75 \%$ of the refractive error blindness, with high hyperopia and aphakia contributing $12.5 \%$ each.

Table 3: Refractive error blindness in the study population

\begin{tabular}{|ccr|}
\hline Type of Error & Number & $\%$ \\
\hline High Myopia & 6 & 75.0 \\
\hline High Hyperopia & 1 & 12.5 \\
\hline Aphakia & 1 & 12.5 \\
\hline Total & $\mathbf{8}$ & $\mathbf{1 0 0 . 0}$ \\
\hline
\end{tabular}

Low vision due to refractive error occurred in 30 cases giving a prevalence of $2.5 \%$. Myopia accounted for $50 \%$ of cases of low vision while hyperopia and astigmatism accounted for $30 \%$ and $16.7 \%$ respectively. Aphakia was the least cause of low vision in the study population (3.3\%).

Table 3: Refractive error blindness in the study population

\begin{tabular}{|c|cc|}
\hline Type of Error & Number & $\%$ \\
\hline Myopia & 15 & 50 \\
\hline Hyperopia & 9 & 30 \\
\hline Astigmatism & 5 & 16.7 \\
\hline Aphakia & 1 & 3.3 \\
\hline Total & $\mathbf{3 0}$ & $\mathbf{1 0 0 . 0}$ \\
\hline
\end{tabular}




\section{DISCUSSION}

This study found a refractive error blindness prevalence of $0.68 \%$. This is comparable to similar studies conducted in Kenya, China and the United States of America. In Kenya, Schwab et $\mathrm{al}^{11}$ found a prevalence of $0.5 \%$ while in China ${ }^{6} \mathrm{Li}$ et al found a prevalence of $0.4 \%$. Among American blacks Tielsch and co-workers ${ }^{5}$ found a prevalence of $0.33 \%$. However, this is at variance with findings of previous authors. ${ }^{1,2,4,12}$ In Lebanon, Mansour et $a l^{4}$ found a prevalence of $0.08 \%$ while in Ethiopia ${ }^{2}$, a prevalence of $0.04 \%$ was recorded. In Tunisia $^{12}$ and Turkey $^{1}$, a prevalence of $0.05 \%$ respectively was found by Ayed and co-workers and Negrel et al.

Even with the use of presenting visual acuity in the definition of blindness, there is still no uniformity in the definition of blindness as some authors use visual acuity of $<3 / 60$ in the better eye while others use $<6 / 60$. Also in some of the studies, all age groups were involved while in others the study was confined to adult population over the age of 40 or 50 years. These may explain why the findings of this study is at variance with those of some researchers as earlier stated.

Myopia was the principal cause of blindness in this study followed by hyperopia and aphakia. This is same as the findings in India ${ }^{7}$, China ${ }^{6}$ Austrailia $^{13}$ and Lebanon ${ }^{4}$. However, this is at variance with studies conducted in Turkey ${ }^{1}$, Ethiopia ${ }^{2}$ and Tunisia $^{12}$. In Turkey, Ethiopia and Tunisia, refractive error blindness was caused solely by aphakia. Myopia is responsible for much of the uncorrected refractive error in the world ${ }^{14}$.The pattern, distribution and impact of refractive errors is largely affected by genetic and environmental factors ${ }^{15}$. This may explain why the findings of this study is at variance with those of some researchers as stated earlier.

In Nigeria, cataract surgery is largely done with the insertion of an intraocular implant. All the cases of aphakia seen in this study resulted from the activities of couchers. Although, relatively rare in occurrence, health education is still needed to stem the activities of couchers in this population.

In most societies, ignorance is a major obstacle to the correction of refractive error especially myopia, as most common objects is within their range of vision. There is therefore in such societies a large number of people that are blind due to refractive error. Uncorrected blindness and low vision due to refractive error may pose a risk to society as some may find themselves in occupation such as driving. Health education on the availability of accessible and affordable refractive error services is needed to stem the tide of needless blindness due to refractive error and avoid its potential danger.

Being a hospital based study, the findings of this study may completely not reflect the actual situation in the population. A state wide survey is preferable and therefore recommended. However, in the absence of such population based data at present, our study and its findings remain relevant.

Uncorrected refractive error is potentially blinding with a prevalence of $0.68 \%$ in this population, myopia being responsible for majority of cases. Health education is needed to create awareness on the availability of refractive error services in this population in order to stem the tide of needless blindness. 


\section{REFERENCES}

1. Negrel AD, Minnasiun DC, Sayek F. Blindness and low vision in South-east Turkey. Ophthalmic Epidemiology. 1996; 3: $127 i$ 134.

2. Zerihun N, Mabey D. Blindness and low vision in Jimma zone, Ethiopia: result of a population based survey. Ophthalmic Epidemiology.1997; 4:19 ï 25.

3. Memon MS. Prevalence and causes of blindness in Pakistan. Journal, Pakistan Medical Association. 1992; 42: 196 ï 198.

4. Mansour AM, Kassak K, Chaya M, Hourani T, Sibai A, Alameddine MN. National survey of blindness and low vision in Lebanon. British Journal of Ophthalmology. 1997; 81: 905 ï 906.

5. Tielsch JM, Sommer A, Kathe W, Katz J, Royall RM. Blindness and visual impairment in an American urban population; the Baltimore Eye Survey. Archives of Ophthalmology. 1990; 108: 286 ï 290.

6. Li S, Xu J, HE M, Wu K, Munoz SR, Ellwein LB. Survey of blindness and cataract surgery in Doumen County, China. Ophthalmology.1999; 106: 1602 ï 1608.

7. Dandona L, Dandona R, Marmamula S, Pyda G, Kovai $\mathrm{V}$, Mudigonda $\mathrm{N}$ et al. Blindness in the Indian state of Andhra Pradesh. Investigative Ophthalmol and visual sci. 2001; 42: 908 ï 916.
8. Dandona $\mathrm{R}$, Dandona $\mathrm{L}$. Refractive error blindness. Bulletin. World Health Organisation. 2001; 79: $237 \ddot{i}$ 243.

9. Fotouchi A, Hashemi H, Raisi B, Mohammed K. Uncorrected refractive errors and spectacle utilization rate in Tehran: the unmet need. British J. Ophthalmology.2006; 90: 534 ï 537.

10. Thylefors B, Negrel AD, Pararajasegram R, Dadzie KY. Available data on blindness (Update 1994). Ophthalmic Epidemiology. 1995; 2: 5 ï 39.

11. Schwab L, Steinkuller PG. Visual disability and blindness secondary to refractive error in Africa. Soc Sci Med,1983;17:1751-1754.

12. Ayed $S$, Negrel $A D$, Nabli $M$, Kamel N, Jabri AM, Siddhom M, Prevalence and causes of blindness in Tunisia Republic ï Results of a National survey conducted in 1993. Sante, 1998; 8: 275 ï 282.

13. Van Newkirk. The causeSpecific Prevalence of bilateral visual impairment in Victoria, Australia: the Visual impairment project. Ophthalmology,

14. MCCarty CA. Uncorrected refractive error. British Journal of Ophthalmology. 2006; 90: 521 ï 522.

15. Abraham D. Duke ï Elders Practice of Refraction. $9^{\text {th }}$ Edition, Edinburgh. Longman Group Limited, 1978; 204. 